\title{
Correction to: Domestic cats (Felis catus) prefer freely available food over food that requires effort
}

\author{
Mikel M. Delgado ${ }^{1}\left(\mathbb{0} \cdot\right.$ Brandon Sang Gyu Han ${ }^{1} \cdot$ Melissa J. Bain ${ }^{1}$
}

Published online: 18 August 2021

○) Springer-Verlag GmbH Germany, part of Springer Nature 2021

\section{Correction to: Animal Cognition}

$$
\text { https://doi.org/10.1007/s10071-021-01530-3 }
$$

Following publication of the original article, the authors identified an error in the author name of Brandon Sang Gyu Han.

The incorrect author name is: Brandon Sang Gyuc Han The correct author name is: Brandon Sang Gyu Han

The author group has been updated above and the original article has been corrected.

Publisher's Note Springer Nature remains neutral with regard to jurisdictional claims in published maps and institutional affiliations.

The original article can be found online at https://doi.org/10.1007/ s10071-021-01530-3.

Mikel M. Delgado

mmdelgado@ucdavis.edu

1 Department of Medicine and Epidemiology, School of Veterinary Medicine, University of California, Shields Ave, 2108 Tupper Hall, Davis, CA 95616-5270, USA 